\title{
METABOLISM OF PECTENOTOXINS IN BROWN CRABS Cancer pagurus FED BLUE MUSSELS Mytilus edulis
}

Thesis: ZhaoxinLi submitted this thesis for his Doctorate in Food Sciences at China Ocean University, China, 2008.

Advisor: Professor Morden Sandvik and Professor Li Hong

ABSTRACT: Pectenotoxins (PTXs) are a group of marine algal toxins which have been found in dinoflagellates and shellfishes. In the present study the metabolism of pectenotoxins in brown crabs Cancer pagurus was investigated. The feeding experiments were carried out at Tjärnö Marine Biological Laboratory in Sweden in September of 2006. Brown crabs, both male and female with all body parts intact, were collected at 15 to $25 \mathrm{~m}$ depth of the coast of Tjärnö. The toxic blue mussels Mytilus edulis (211.4 $\mu \mathrm{g} / \mathrm{kg}$ PTX-2, 2,781.4 $\mu \mathrm{g} / \mathrm{kg}$ PTX-2 SA, $236.3 \mu \mathrm{g} / \mathrm{kg}$ 7-epi-PTX2 SA, $138.3 \mu \mathrm{g} / \mathrm{kg}$ PTX-12a and $138.7 \mu \mathrm{g} / \mathrm{kg}$ PTX-12b) were sampled from south coast of Norway. The crabs were kept in individual cages in tanks with continuous pumping of deep sea water at temperatures ranging from 10 to $12^{\circ} \mathrm{C}$ during the experiment. Brown crabs were fed toxic blue mussels for 21 days and depurated for 42 days. Toxins were extracted with methanol from the digestive glands of contaminated crabs, uncontaminated crabs (control group) and blue mussels. Extracts of crab digestive glands and mussel meat were fractionated by liquid-liquid partitioning and analyzed by liquid chromatography coupled with tandem mass spectrometry. Comparison among the chromatograms of extracts revealed the presence of PTX-2, PTX-2 SA, 7-epi-PTX-2 SA, PTX-12 and a new PTX-like compound which was designated metabolite-1 in crabs. The concentrations of PTXs in the crabs were analyzed during the depuration. A one-compartment model was applied to describe the depuration of PTXs. The half-life of PTX-2, PTX-2 SA, 7-epiPTX-2SA, PTX-12a, PTX-12b and metabolite-1 were estimated to be respectively $6.5,6.0,6.5,7.5,7.5,7.0$ days. After a 42-day depuration the amount of PTXs measured in crab digestive glands was less than $1 \mu \mathrm{g} / \mathrm{kg}$. The metabolite-1 in crab 
digestive glands was extracted with methanol, purified by solid phase extraction with silica gel 60 (Merck) columns and analyzed by liquid chromatography coupled with ion trap mass spectrometry. The LC-MS2 mass spectrum of metabolite-1 [M+Na]+ ion at $\mathrm{m} / \mathrm{z} 897.5$ showed fragment ions at $\mathrm{m} / \mathrm{z} 853.5$ and 555.5 typical of those exhibited by other pectentoxins. The molecular weight of metabolite-1 was 874 , the same of PTX-11. The OH group in the molecular of metabolite-1 was somewhere in the C16-C33 fragment.

KEY WORDS: pectenotoxins, Cancer pagurus, Mytilus edulis, metabolisim, accumulation, depuration, LC-MSMS.

\section{CORRESPONDENCE TO:}

ZHAOXIN LI, China Ocean University, Yellow Sea Fishery Research Institute, 106, Nanjing Road, 266071 Qingdao, China P.R. Phone: +86 858363 48. Email: zhaoxinnw@hotmail.com. 